\title{
South African Grade 5 non-native learners learning Mandarin as a second additional language with a focus on Chinese characters
}

\begin{tabular}{|c|c|}
\hline \multicolumn{2}{|c|}{$\begin{array}{l}\text { Authors: } \\
\text { Norma M. Nel } \\
\text { Soezin Krog } \\
\text { Lazarus Lebeloane }^{3}\end{array}$} \\
\hline $\begin{array}{l}\text { Affiliations: } \\
{ }^{1} \text { Department } \\
\text { of Education, } \\
\text { Education, Un } \\
\text { South Africa, } \\
\text { South Africa }\end{array}$ & $\begin{array}{l}\text { Psychology } \\
\text { College of } \\
\text { iversity of } \\
\text { retoria, }\end{array}$ \\
\hline $\begin{array}{l}{ }^{2} \text { Department } \\
\text { Childhood Edu } \\
\text { of Education, } \\
\text { South Africa, P } \\
\text { South Africa }\end{array}$ & $\begin{array}{l}\text { f Early } \\
\text { Ication, College } \\
\text { University of } \\
\text { retoria, }\end{array}$ \\
\hline $\begin{array}{l}{ }^{3} \text { School of Edu } \\
\text { of Education, } \\
\text { South Africa, } P \\
\text { South Africa }\end{array}$ & $\begin{array}{l}\text { cation, College } \\
\text { Jniversity of } \\
\text { retoria, }\end{array}$ \\
\hline $\begin{array}{l}\text { Correspondin } \\
\text { Norma Nel, } \\
\text { tnelnm@unisa }\end{array}$ & $\begin{array}{l}\text { g author: } \\
\text { ac.za }\end{array}$ \\
\hline $\begin{array}{l}\text { Dates: } \\
\text { Received: } 28 \mathrm{~S} \\
\text { Accepted: } 04 \mathrm{~F} \\
\text { Published: } 16\end{array}$ & $\begin{array}{l}\text { ept. } 2018 \\
\text { =eb. } 2019 \\
\text { May } 2019\end{array}$ \\
\hline $\begin{array}{l}\text { How to cite th } \\
\text { Nel, N.M., Kro } \\
\text { Lebeloane, L., } \\
\text { 'South African } \\
\text { non-native lea } \\
\text { Mandarin as a } \\
\text { additional lang } \\
\text { focus on Chine } \\
\text { Literator } 40(1) \\
\text { https://doi.org } \\
\text { v40i1.1557 }\end{array}$ & $\begin{array}{l}\text { is article: } \\
\text { g, S. \& } \\
2019, \\
\text { Grade } 5 \\
\text { rners learning } \\
\text { second } \\
\text { guage with a } \\
\text { se characters', } \\
\text {, a1557. } \\
\text { /10.4102/lit. }\end{array}$ \\
\hline $\begin{array}{l}\text { Copyright: } \\
\text { C 2019. The A } \\
\text { Licensee: AOS } \\
\text { is licensed unc } \\
\text { Creative Comn } \\
\text { Attribution Lic }\end{array}$ & $\begin{array}{l}\text { uthors. } \\
\text { IS. This work } \\
\text { ler the } \\
\text { nons } \\
\text { ense. }\end{array}$ \\
\hline Read online: & \\
\hline 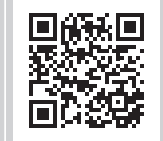 & $\begin{array}{l}\text { Scan this QR } \\
\text { code with your } \\
\text { smart phone or } \\
\text { mobile device } \\
\text { to read online. }\end{array}$ \\
\hline
\end{tabular}

The South African Department of Basic Education (DBE) listed Mandarin as a second additional language (SAL) (Grades 4-9) in the National Curriculum Statement Grades R to 12 in 2015. We identified a gap in current research regarding the learning of Chinese characters by non-native learners of Mandarin as an SAL. The great number of characters, their complexity and the absence of grapheme-phoneme correspondences put a huge strain on learners' memory. Rote learning and repetitive exercises lead to boredom and lack of motivation to learn Mandarin. A qualitative research design (case study) was employed in this study. Individual and focus group interviews, questionnaires, classroom observation and a Chinese characters exercise for researchers were used as data collection tools. The data were analysed manually using an inductive process and organised according to categories, themes and conclusions. The study highlights how South African Grade 5 learners learning Mandarin as a SAL learn the Chinese characters and the challenges they encounter. We consider the educational implications for learning Chinese characters and offer recommendations.

Keywords: Mandarin; second additional language; learning Chinese characters; non-native learners; challenges; educational implications.

\section{Introduction}

The aim of this research was to explore and gain a better understanding of how South African Grade 5 learners learning Mandarin as a second additional language (SAL) learn Chinese characters. We found what challenges are involved and the educational implications for learning Chinese characters in the South African context. The study was guided by three research questions stated in the research methodology section of this article.

The South African Department of Basic Education made provision to list (and an incremental implementation of the roll-out) of Mandarin as a SAL in grades 4-9 in the National Curriculum Statement Grades R to 12 (AllAfrica.com 2016; Department of Basic Education 2015:3). The teaching of Chinese in English primary schools is in its infancy and the teaching approaches vary on an experimental continuum (Li 2013:293). As Chinese ${ }^{1}$ is completely different from English, this cognate difference has implications for the way Mandarin is acquired and taught (Li 2013:62). Learning Chinese characters is labour-intensive as well as time-consuming, which means other language skills do not earn as much time as instruction on characters (Poole \& Sung 2015:59).

Sung and $\mathrm{Wu}$ (in Li 2013:66) explain that the meaning and the sound of each Chinese character must be mastered by rote learning, and that there are 3000 commonly used characters of the 87019 characters that shape the language. Meanings are represented by these complex Chinese characters, but they do not indicate the pronunciation. Shen (in Xu, Perfetti \& Chang 2014:773) posits that the challenges in learning Chinese as a foreign language lie in remembering the form, sound and meaning of characters. The number of characters, visual complexity of graphemes and the fact that there is no systematic grapheme-phoneme correspondence exacerbate the problem.

Li $(2013: 295,299)$ in her study in the UK found that, in some cases, the learners found practising characters boring and, in other cases, they found stroke practice and number practice boring.

1.Chinese is regarded as a single language; however, it has great regional variation. With regard to spoken chinese, there are seven related language families which encompass more than 1000 dialects. The Chinese government has made Standard Mandarin (Putonghua) the common language of Chinese speakers (Ding \& Saunders 2006:31). In this article, the references use Chinese and Mandarin interchangeably, but the authors chose to use Mandarin henceforth. 
The way that Chinese is taught exerts an influence on how difficult the learners perceive the learning of Chinese to be.

Furthermore, Shen (2005:53, 61-62) refers to 'orthographicknowledge-based strategies' and Tan et al. (2005:8781) also emphasise the importance of orthographic awareness that learners need to acquire. Tong, Yip and Yip (2015:173-177) explain the importance of phonetic and semantic radicals, hence the necessity of teaching radicals. The Pinyin approach is advocated by McBride-Chang et al. (2012:283) in an effort to read the Chinese characters.

In view of the above findings regarding Chinese character learning and its challenges, we considered it as a research gap worth exploring. Learning Mandarin as a SAL is in its infancy in South Africa. Thus, proactive research endeavours need to inform teachers and education officials about effective teaching and learning strategies in the acquisition of Mandarin. In their study, Xu, Li and Curtis (2015:58) focussed on the influence of transcultural research on teachers' reflective practices. We therefore need to bear in mind many other contexts before arriving at an all-embracing practice. Moeller and Catalano (2015:331) postulated that action research is one of the most effective research methodologies for foreign language learning and teaching. Teachers interrogate their own instructional practices and are able to change their teaching practices. In this study, we were able to ascertain the teaching and learning practices for Chinese characters in the South African context.

\section{Literature review}

\section{Chinese characters}

Shen (2005:50) claims that what makes Chinese so challenging to learn is the nature of Chinese orthography and the graphic configuration of characters which are extremely complex. Chinese written words are made up of characters, radicals ${ }^{2}$ and strokes. Although there are many different types of strokes, no rules exist regarding the number of strokes a character can contain. Several attempts have been made to simplify the characters, for example, 门door (simplified) and 門 door (traditional) (Schmidt 2002:23).

The characters represent morphemes and are written as individual units with spaces in between. For example, 开 (kāi) with its own meaning of 'open/start' contributes to the meaning of the word 开关 (guān-close), which means on-off switch (Hau-Yoon 1999:5). With every character written, a syllable corresponds in the language spoken and every character or syllable has a meaning. Either a word or a morpheme (meaning) makes up a multi-character word (Tse et al. 2007:376). There is no sound-script correspondence. Therefore, the foundation of reading and writing in Chinese involves automatic character recognition and production (Shen 2005:50).

\footnotetext{
2.'Radicals are the basic orthographic units in characters. They can be further classified into two categories: phonetic radicals and semantic radicals. Theoretically, into two categories: phonetic radicals and semantic radicals. Theoretically, a
phonetic radical represents the sound of a character and a semantic radical provides clues to the meaning of the character' (Shen 2005:50).
}

\section{Chinese character learning}

Rote memorisation, graphic and context cues, and knowledge of radicals form the foundation of learning Mandarin. In Shen's $(2005: 53,61,62)$ study, it was found that 'orthographic-knowledge-based strategies' are often deployed. It helps to develop links between visual symbols, phonology and semantics. Motor programmes need to be established in order to form long-term memory of the Chinese characters (Tan et al. 2005: 81, 87). The four basic aspects - radical knowledge, graphemics, and phonetics and semantics - are used as cues to encode and decode characters. Tong et al. (2015:173-177) explain that when Chinese foreign language (CFL) learners 'encode positional, phonological and semantic information of radicals in character learning', semantic radicals are more important than phonetic radicals. Non-native learners use radical knowledge to learn characters as they look for 'soundshape-meaning connections' in a character. The reason for this is that the Chinese script is logographic in nature. However, where beginner learners have very little orthographic knowledge, it would limit them in learning characters and therefore they would not use orthographicknowledge-based strategies. It is, thus, necessary that orthographic knowledge, particularly radical knowledge, should be introduced systematically to beginner learners (Shen 2005:53, 61, 62).

It is therefore important for explicit teaching of radicals as this helps CFL learners to learn the specific characters. Furthermore, $\mathrm{Xu}$ et al. (2014:789) propose that sequencing radical-sharing characters is an advantage for the beginner learner regarding the form, sound and meaning representation of the characters.

Shen (2005:57) identifies strategies commonly used by learners of Chinese. Some of the most salient strategies include paying attention to tone and associating it with Pinyin, reviewing new words and writing them repeatedly, associating strokes with a similar character learnt, recognising radicals learnt before, attending to stroke order and learning that the sound is associated with the meaning and shape of the character before memorising the new character.

It is important to note the role of Pinyin in the learning of Chinese characters. Pinyin is a phonological coding system (alphabet) that represents the pronunciation of Chinese characters using Roman alphabet letters as well as 'lexical tone transcriptions'. Pinyin is thus used as an aid to learn to read instead of 'reading itself in Chinese' (McBride-Chang et al. 2012:284). The Pinyin alphabet letters are similar to the sounds in their English alphabet (Poole \& Sung 2015:61). Learners are also faced with the four speech tones, namely, high level, rising, falling-rising and falling, which are represented by symbols. However, for Pinyin, tone numbers such as 1, 2, 3 and 4 are added at the end of each syllable to indicate which tones must be used to pronounce the word or words (McBride-Chang et al. 2012:284). 


\section{Theoretical framework The phenomenographic approach}

The phenomenographic approach is applicable whereby learning would start with the learners' own language. The Chinese characters are introduced and used within meaningful contexts for the learners. The integration of language learning and the awareness thereof is central to this approach. The learners' perceptions of what they need to learn and how these perceptions are formed are pivotal to this approach. Learners' attention is drawn to the structural features, the written form and the pronunciation in a systematic way. Learners learn the characters 'in relational clusters, similarities among related characters in the clusters ...' (Tse et al. 2007:375). Learners are assisted by the teachers to emphasise the crucial aspects of the characters and the words.

\section{The Pinyin-annotated approach}

Yongbing (2005:409-412) offers a way forward in learning the Chinese characters, namely, the Pinyin-annotated approach of teaching Mandarin Chinese and its implications for the wider language and literacy education community, internationally. However, character recognition and writing characters are taught systematically, 'each of the digraphic systems is used as a pedagogic and mnemonic device for the other', but it is not the main focus of this approach. The Pinyin approach is regarded as the fast track whilst the learning to read and write characters is regarded as the slow track. This approach makes it easier for the teacher and the learner as it is learner-centred; the learner is encouraged to read extensively in and out of class using Pinyin. This approach also facilitates the learners' learning how to read and write sooner and also helps to sustain their motivation and interest. There are, however, prerequisites for using this approach, for example, adequate Chinese material with Pinyin annotations and context-specific problems should be taken into account, such as viewing English as the Language of Learning and Teaching (Yongbing 2005:409-412).

\section{Research methodology}

The researchers sought to answer the following research questions:

- How do South African Grade 5 non-native learners learning Mandarin as a SAL learn Chinese characters?
- What challenges do South African Grade 5 non-native learners learning Mandarin as a SAL face when learning Chinese characters?

- What are the educational implications of learning Chinese characters for South African Grade 5 non-native learners studying Mandarin as a SAL?

\section{School context and participants}

The participating school, namely, a private school (which is called a Chinese school) in the Gauteng province, caters for all learners who wish to enrol, irrespective of their race, religion and home language, and thus not only for native Chinese learners. The school has an adjacent pre-school and offers the Curriculum Assessment Policy Statement (CAPS) from Grade R to Grade 12. The school offers Mandarin as the language of learning and teaching (LoLT) to native Chinese learners. The South African Grade 5 learners learning Mandarin as a SAL are taught Mandarin during a 30-min lesson on a daily basis; hence, they do not have a high level of proficiency. However, their English level of proficiency is good.

The participating teacher teaching Mandarin is Taiwanese and is fluent in speaking and writing Mandarin. She received her teacher training in a South African university and has a few years of teaching experience, teaching Mandarin as a foreign language. Purposive sampling was used to select the participants, that is, the Grade 5 learners, comprising 20 learners who started the formal learning of Chinese characters in this grade, as we believe that they are representative of the group we wanted to study (see Table 1).

\section{Research design}

A qualitative research method, in the form of a case study, was used in this article. The focus was on South African Grade 5 learners learning Mandarin as a SAL, with an emphasis on Chinese characters. They were interviewed about their 'lived experiences' of learning Chinese characters in a South African school. The participants were regarded as 'individuals bounded in time and place' (McMillan \& Schumacher 2014:32).

\section{Data collection}

Data collection tools comprised a semi-structured interview with the principal for the purpose of gaining permission to

TABLE 1: Ethnographic backgrounds of participants.

\begin{tabular}{|c|c|c|c|}
\hline Participants' ethnicities & $\begin{array}{l}\text { Participants' language } \\
\text { backgrounds }\end{array}$ & $\begin{array}{l}\text { Influence of participants' L1 in } \\
\text { learning Mandarin }\end{array}$ & Common qualities of participants \\
\hline $\begin{array}{l}\text { - Romanian (1) } \\
\text { - Greek (1) } \\
\text { - Black South African (majority) } \\
\text { - White South African }\end{array}$ & $\begin{array}{l}\text { - Romanian and English } \\
\text { - Greek and English } \\
\text { - isizulu, Setswana and English } \\
\text { - Sesotho } \\
\text { - English } \\
\text { - Sesotho and Sepedi } \\
\text { - English and Sesotho } \\
\text { - English and Afrikaans }\end{array}$ & $\begin{array}{l}\text { - Learners who started learning Mandarin } \\
\text { in pre-school (the majority) were less } \\
\text { dependent on their L1 than those who } \\
\text { joined the class in subsequent years. }\end{array}$ & $\begin{array}{l}\text { - All Grade } 5 \text { learners. } \\
\text { - LoLT is English. } \\
\text { - All the learners follow the same curriculum. } \\
\text { - All the learners do extra-mural activities such as Chinese cultural } \\
\text { activities. } \\
\text { - All the learners started to learn formal Chinese characters in } \\
\text { Grade } 5 \text {. } \\
\text { - The learners have no cultural connection to Mandarin and have } \\
\text { no Oriental origins/background. Thus they have no cultural or } \\
\text { other relations to logographic writing. }\end{array}$ \\
\hline
\end{tabular}


conduct research and background information regarding the school, to inform the principal what the research entails and the expected outcomes and to discuss logistics; a semistructured interview with the teacher regarding her teaching strategies for Chinese characters and subsequent informal discussions after data collection sessions; three focus group interviews (six learners per group); four individual learner interviews (pseudonyms - Sun, Moon, Star and Meteor) were conducted for triangulation purposes. A lesson observation schedule was completed using descriptive and reflective field notes (Efron, Efron \& Ravid 2013:88-90). A Chinese characters exercise was completed by the three researchers with the assistance of three volunteer learners. Parent and learner questionnaires (open-ended) were also administered. The multiple data collection tools were used continuously until saturation point was reached, that is, a point where no more new data emerged for analysis (Wilson 2009:65).

\section{Data analysis}

The focus group learner interviews served a two-pronged purpose: as the main source of data and to build a relationship of trust with the learners selected for the individual interviews.

A transcriber copied and recorded the interviews and the researchers identified themes and categories manually. To ensure trustworthiness, McAteer (2013:135) recommends starting with a simple narrative and then building layers on it in an effort to access as much of the case study as possible, reviewing and reflecting, which is a form of triangulation, resulting in reliable and trustworthy content. These layers complemented, illustrated and substantiated themes and categories identified with the data collected through questionnaires, a lesson observation, individual learner interviews and a Chinese characters exercise (by the three researchers and three learners).

\section{Ethical considerations}

An ethical clearance certificate was obtained from the University of South Africa College of Education's Ethics Review Committee on 15 February 2017 (reference number 2017/02/15/1127381/30/MC).

\section{Key findings and discussion}

\section{Themes and categories}

The following keys were used for interview responses for focus group and individual interviews:

- Focus group 1 (six learners): FG1-1 to FG1-6;

- Focus group 2 (six learners): FG2-1 to FG2-6;

- Focus group 3 (six learners): FG3-1 to FG3-6

- Individual learner interview (pseudonyms): Sun, Moon, Star and Meteor

- Learner (respondents to questionnaire): L1-5
- Parents (questionnaire responses): P1.....P14 (14 questionnaires were returned).

- Mandarin teacher, female, Grade 5: MTFGR5

Theme 1: Teacher's Chinese character teaching strategies: The teacher explained:

'The content is basically about school life and the communicative approach. So the teaching is about everyday conversation. Cultural learning is part of the grammar lessons and character writing lessons. This is to give the learners more background stories about the use of sentence structures and formation of a character.' (MTFGR5, Mandarin teacher, female, Grade 5)

Vaezi, Tabatabaei and Bakhtiarvand (2014:171) recommend that syllabus designers should make use of the classification of speech into categories such as requesting, inviting, complaining and apologising as these are universal in all the languages.

The teacher starts her lessons with listening followed by speaking, reading and, lastly, writing. Tse et al.'s (2007:375) phenomenographic approach to learning Chinese characters begins with the learners' own language and introduces characters and uses them in the learners' meaningful contexts. Systematically, their attention is drawn to the structural features, the written form and the pronunciation.

The teacher stated 'Chinese characters are more distinctive than Pinyin'. She distinctly feels that characters are easier for the learners to learn than tone which she perceives as confusing. The characters should be introduced when communication demands it. She said:

'The learners learn through context. So, whenever, they are in the situation, they would use the appropriate word. Chinese writing in Pinyin can be very confusing as one sound can have more than one associated character which conveys more than one meaning.' (MTFGR5, Mandarin teacher, female, Grade 5)

She further elaborated 'I think learners can begin to learn Pinyin and characters as early as possible; however, I would introduce Pinyin first'. Parents and teachers in China already teach the learners Pinyin in the beginning stages of Chinese character learning, seeing that it is quite simple in comparison to Chinese character learning. They use either sheer memorisation ignoring the phonological properties or by concentrating on the phonological coding (McBride-Chang et al. 2012:284).

The teacher explained that learners learn a set of characters in every new chapter (in their workbooks). Their bank of characters is built on as they carry on. Firstly, she teaches the sound, then the meaning and, lastly, the use of the Chinese character sequence, which is strokes and rules of writing a character, the radicals, then the associations and pictures associated with the characters, if any are used. This approach is recommended for beginner learners. She also added that it is very helpful to demonstrate the evolution of Chinese characters. 
Regarding teaching the sounds of the characters, she explained: 'we first drill the sound of the character'. Sung and $\mathrm{Wu}$ (2011:685) found that because there is a difference between characters and their pronunciation, it becomes challenging for non-native learners to learn Chinese characters, whereas a skilled Chinese reader is able to use their radical knowledge and orthographic functions in order to read. The teacher explained that:

'... they learn to recognise the characters in a text and we drill the character repetitively - like reading a signpost, as frequently as possible using worksheets and games'. (MTFGR5, mandarin teacher, female, Grade 5)

Tse et al. (2007:375) alludes to the traditional way of learning Chinese characters, which is copying them repeatedly until they can:

'... reproduce their form and pronunciation from memory [with the emphasis being on how to write characters].' (Tse et al. 2007:375).

This takes years and the learners experience it as laborious and boring (Tse et al. 2007: 375).

For learners to recognise and write the characters, the teacher in this study read from the texts and explained the meaning in context. She then guided them to identify vocabulary in the text and the characters. This reflects a top-down approach. The main challenge that the teacher experienced was:

'... when the learners do not follow the sequences of writing a character'. (MTFGR5, Mandarin teacher, female, Grade 5)

According to Sung and $\mathrm{Wu}(2011: 685)$, it is necessary to teach non-native learners to use learning strategies (in this case, identifying vocabulary) as this enables them to manage their language learning. It can be deduced that character learning strategies used most frequently are cognitive (Sung \& Wu 2011:696). Tse et al. (2007:375, 384) developed a learning approach, which is a perceptual approach to learning Chinese characters and is inspired by the phenomenographic theory of learning where the emphasis is on perceptual experiences.

Learners are given homework. They receive a worksheet with characters to practise. The worksheet has blocks and the learners have to practise writing each character block by block. In order to maintain their interest, the teacher recommends that learners listen to Chinese music and watch Chinese movies with characters and Pinyin and English subtitles - she extends their learning to practical realities. She said:

'More time and a learner-friendly environment to support learning characters and appropriate visual aids and animated characters could help learners to understand and memorise.' (MTFGR5, Mandarin teacher, female, Grade 5)

The main challenge that the teacher experiences is when the learners do not follow the sequences of writing a character.

The learners' work is assessed by the teacher in order to report on the progress of the learners' competence in learning the Chinese characters. The teacher observed that the sequence of strokes helps them to look up the unknown character in the dictionary as one of the ways of learning it. Rather than using Pinyin to look up in the dictionary, they can just look at the character and count the number of strokes and find the character accordingly.

She reported that the ultimate aim to evaluate the success of the lessons was when the learners were able to communicate proficiently over social media and technology without difficulties. By the end of the year, the teacher expected that the learners would be able to use a larger bank of characters in writing. They must be able to construct basic and meaningful sentences in characters only.

Lesson observation: The classroom environment was devoid of Chinese characters as only three calendar pictures were stuck on the back wall. The teacher used a computer and data projector to introduce her lesson on the history of the characters and asking learners what they found unique about the character, for example, asking learners to label objects such as a flower. They shouted the answer out in unison. Next, the learners were allocated numbers (in Mandarin) and then they were grouped into three groups. They were instructed in English to play a card game where they needed to match characters, pictures and modern objects with traditional characters. Her instructions were clear and learners cooperated. The groups were rather noisy, but they enjoyed the activity and participated enthusiastically. The teacher walked around and attended to learners' problems patiently. At the end of the period, the teacher checked to see who had the most correct answers. The top achievers were praised and they received marshmallows as incentives. The duration of the lesson was $30 \mathrm{~min}$.

Theme 2: Volunteer learners and researchers - Chinese characters practical exercise: Three volunteer learners from the sampled class were identified to help the three researchers to learn specific characters for $30 \mathrm{~min}$. The purpose of this practical exercise was for the researchers to gain insight into the way the three individual learners learnt the characters (see Table 2).

Learner A introduced the character 人 rén (Pinyin), meaning 'person' or 'people'. He used the blackboard to illustrate how the character is written (the numerical order) and pronounced. Whilst drawing the character, he used the association with the word, namely, that it looks like a person and it has legs and arms. He explained that he kept on practising and once he had mastered writing the character, he would make sentences with the characters he had learnt. We repeated the character and copied from the board as he was writing it.

Learner B introduced the tone signs. She explained that there were four different tone sounds and then drew them on the board, together with examples of Pinyin and 
TABLE 2: Learners assisting researchers to learn Chinese characters.

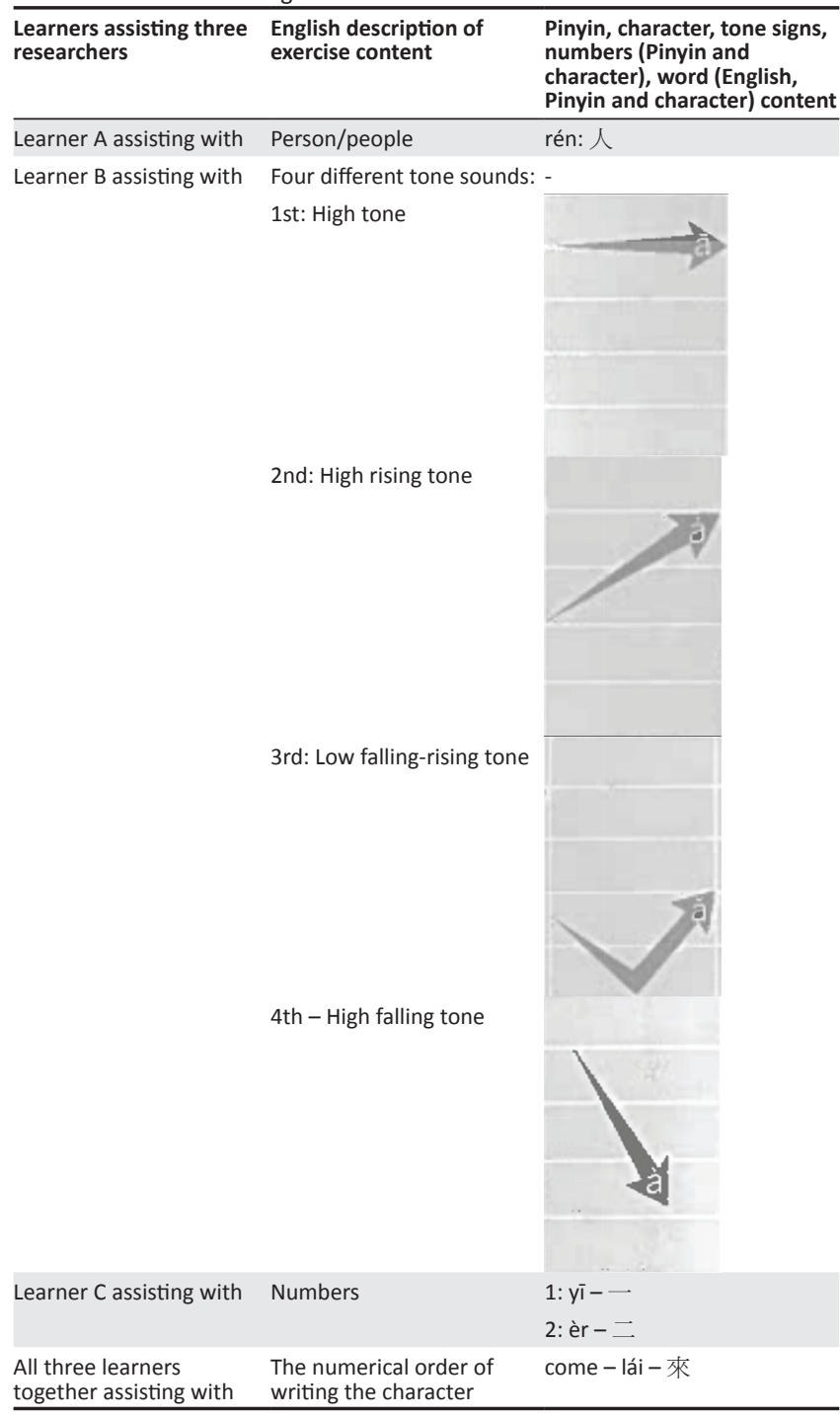

Source: Adapted from Zhilong, F., 2000, Essential Chinese for travellers, Regent, Hong Kong

equivalent English words containing the sounds. She explained how to pronounce the Pinyin and what they meant in English. We repeated after her as she wrote on the board and copied these examples: (1) 馬/媽 Pinyin: $m a \breve{a} / m \bar{a}$ [horse/mom], (2) 還 Pinyin: hái [also], (3) 我 Pinyin: wǒ [I/me], (4)笨 Pinyin: bèn [stupid].

She proceeded to explain that $m \bar{a}$ has a long flowing sound and that de changes the ' $\mathrm{I}$ ' to 'my' and hăo 好 means 'good/ well' as in 'You are good' or 'I am well'. Then, she wrote the character 女孩 Pinyin: nü hái [girl] on the board and combined the two characters to make the sentence 女孩好.

女孩好 can be literally translated as 'girl is good'. 女孩 means 'girl' and 好 means 'good'.

Learner $C$ taught us the writing, pronunciation and the equivalent Roman numerals (Pinyin). She also used association in order to remember the characters, for example, the character for number 4 四 looks like a window with curtains and the character for number 6 六 looks like a person.
The three learners together showed us the character 來 Pinyin: lái [come] and how the character is written in numerical order - in collaboration. Learner A illustrated it on the board, whilst learners B and C explained that anything to do with 'mouth' includes 口 (a square), for example, 'eat/ drink' contains character 吃 Pinyin: chī [eat]. Together they showed us along the same lines how to write the sentence using the characters: 來吃早飯. In Pinyin, it is written as 'lái chī zāo fàn' [come eat breakfast]. By emphasising the phonological properties of the Roman letters in a word 'from an alphabetic orthography' greater literacy skills can be facilitated. In a study by McBride-Chang et al. (2012:284), 'phonological coding system used to teach Chinese in Mainland China, also excel [sic] in Chinese character recognition and writing'. This is partly because Pinyinlearning differs from reading Chinese characters as it is a phonological coding system (it uses an alphabet system to represent, or spell, the pronunciations of Chinese characters using both Roman alphabet letters approximately the same number as those in English and lexical tone transcriptions). Pivotal in learning to read and write in alphabetic orthographies is the alphabetic principle thar letters of the alphabet represent sounds. The key is thus to focus on speech sounds which include phonemes or individual speech sounds and mapping sounds to letters. Chinese characters, on the contrary, represent 'syllable-level sounds' (McBride 2016:526). When a phoneme sound and a letter are connected, it can help a learner with their one-to-one correspondence. Similarly, it can help the learner when learning Pinyin because its sound-letter correspondences are consistent (McBride-Chang et al. 2012:286).

After the practical exercise, we held a reflection session, each voicing our thoughts about how the three learners helped us learn the characters.

The researchers' reflections of the practical exercise: During the exercise, we asked questions and interacted with the three volunteer learners. They were very enthusiastic and helped with the pronunciation and explained important aspects of character writing, such as stroke order (see Figure 1). We realised that it is important for the learners (A, $\mathrm{B}$ or $\mathrm{C})$ to draw the character slowly and talk through it whilst copying it and which strokes are separate or closed and where to start. We needed to repeat and practise such that this could not be done in one exercise. We also needed more time to practise the five tone sounds. Learner B was excellent, whilst learners A and C presented their lessons haphazardly, which caused some confusion. We also realised that in order to learn to write the characters, it was important to also know the accompanying Pinyin, which in turn needed further explanation. It was evident that the whole character seen at first needed to be taken apart and it had to be explained how the radicals were combined to make up the whole character, for example, the number 2, 二, is made up of two lines: the bottom one longer and the top one shorter. Our conclusion was that in order to learn to write characters, it requires copying the character correctly in numerical order 


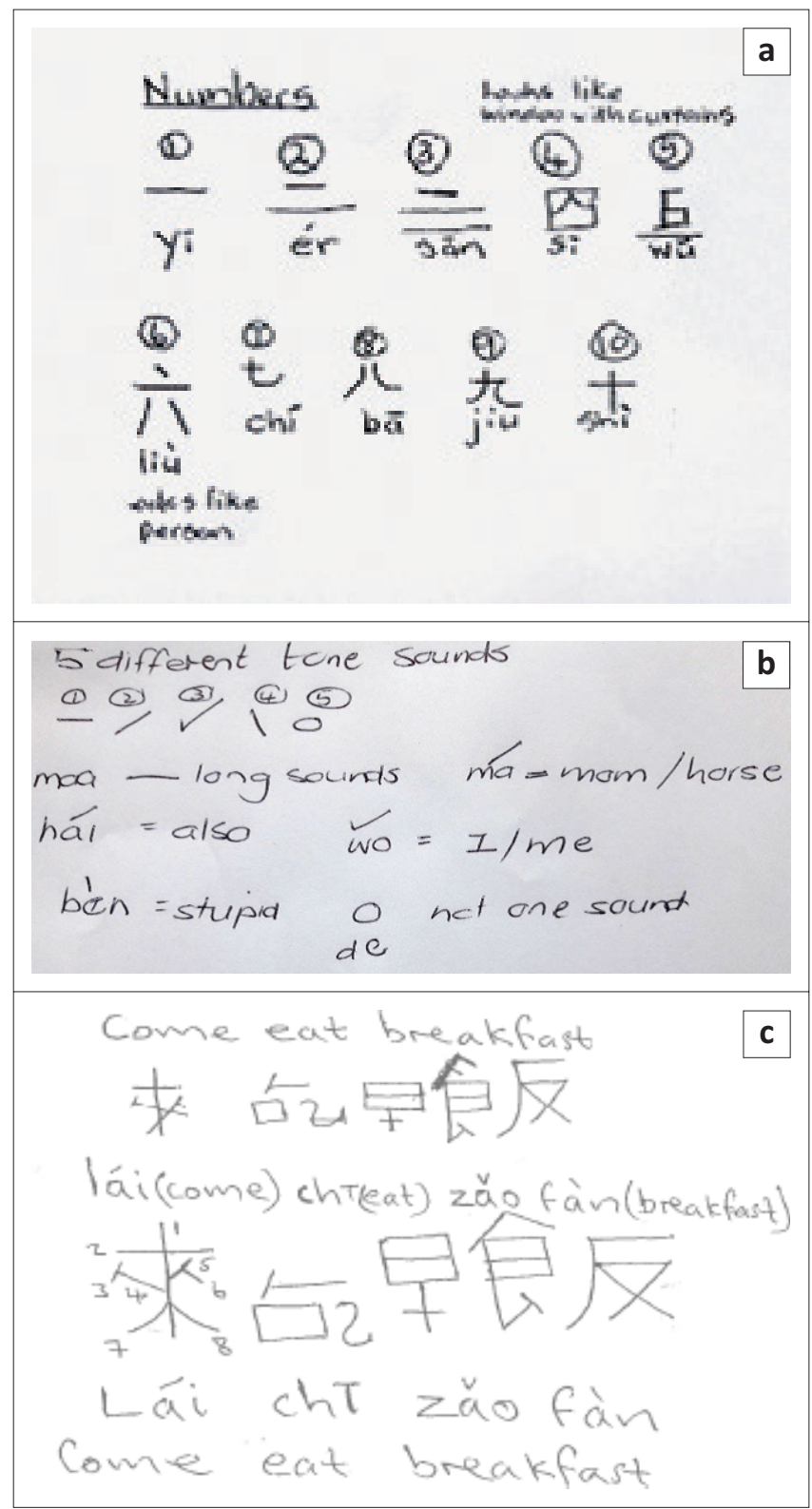

FIGURE 1: Examples of researchers' character writing efforts during the character learning practical exercise: (a) Researcher 1, (b) Researcher 2 and (c) Researcher 3.

writing the characters over and over until one reaches perfection. Li (2013:282) states, as do many other authors, that 'Chinese is a language that has to be learnt by heart, and much memorisation and repetition is demanded in learning it'. Thus, there must be a balance between fun and hard work, which poses a challenge for the teacher teaching Chinese characters. This is a very good exercise for teachers to evaluate their teaching strategies and to adapt their teaching styles effectively to suit the learners' needs.

Theme 3: Learners' Chinese character learning experiences (Learner responses to the questionnaire, individual learner interview responses and learner focus group responses): Based on the examples in Table 3, questions were formulated (Appendix 1) for the learners to answer in the spaces provided.
TABLE 3: Learner questionnaire.

\begin{tabular}{lcl}
\hline Chinese word (Pinyin) & Character & English equivalent \\
\hline Hăo & 好 & Good; well \\
Rén & 人 & Person; people \\
Wǒ & 我 & I; me \\
\hline
\end{tabular}

The participating learners recognised the role of technology in promoting their level of competence in Mandarin. One participant mentioned iPads as a valuable source of communication. Technology has enhanced the way Grade 5 learners communicate and the acquisition of a second language. Colours are especially effective when viewed on a computer or smart phone screen.

The step-by-step method helped learners to memorise and follow the pattern of adding the relevant strokes to build the words. They also used dictation and paid attention to time, as the learners needed enough time to recall the strokes and to write them down. The value of using repetition in internalising the various characters is evident from the learners' responses.

When studying the individual learner responses, it became evident that the learners experienced speaking the language as quite challenging. Once more, there was reference to the use of electronic devices, as one learner referred to using the computer to practise the new words. Concepts were repeated for the purpose of easy recall. The learners also mentioned the translations from English into Pinyin and then into Mandarin. The use of Pinyin was regarded as a stepping stone to eventually master Mandarin. It was also evident that all four skills, listening, speaking, reading and writing, were used to teach Mandarin.

\section{To this effect, Learner Sun said:}

'The one thing that I don't like is the many characters, like say, for example, my name. The characters here take quite long to write, but if you can keep trying, you get it right. I do not like translating English into Chinese. I think I am good at learning characters, because since they give us worksheets, it gives us a chance of knowing which character, which Pinyin you have to learn. Since we learnt the Pinyin, we could carry on to obtain better marks in Mandarin and know more characters.' (Learner Sun, female, Grade 5)

During focus group interviews, the learners' responses reflected much of the teachers' methodology. Games, such as learning each other's names, seemed to be important for the classroom activities. Worksheets are used for memory tests, where learners need to underline and circle the words they hear within a sequence. The participants reported that they had to repeat many times in order to remember the characters. Hence, repetition formed an integral part of the teachers' methodology. The various teaching strategies adopted by the teachers were shared. Other learner responses in the focus groups included comments on reading Chinese books in pairs, doing group work such as listening tests where they have to distinguish between correct or incorrect pronunciation, listening to compact discs (CDs) where the 
words are pronounced and the learners have to repeat the words, and participating in board work. The focus group interviews echoed what was said earlier as the combination of the four language skills was evident. Participants shared their views on the enjoyment of the various skills and working in groups at times, which they also found particularly helpful.

The major concern expressed by FG1-2 is that the:

'... task is hard, but I think we need more time.' (FG1-2, male, Grade 5)

FG1-6 said:

'So we don't really have enough time to work out which character is which, so I think we should actually start taking classes after school so that we can learn more.' (FG1-6, male, Grade 5)

Theme 4: Parental involvement (parent questionnaire responses, individual learner interviews and focus group interview responses): Parents are influential members in the lives of the learners. This crucial supportive role could be detected when analysing the data. Some parents had business connections with the Chinese and they reported that their jobs exposed them to Mandarin.

The parents reported the benefits of being exposed to learning Mandarin through their involvement with their children's learning. They also mentioned the benefits of using technology when practising language acquisition skills. The parents also supported their children with homework and whilst helping their children, they had the advantage of picking up certain elements of learning Mandarin themselves. On a more negative note, one parent said that it is the only area of her child's education that she does not become involved in. The parents were of the opinion that the learning of Mandarin was beneficial to the entire family. Some parents even enrolled other siblings to create family support and encourage group learning of Mandarin. They maintain that if more family members learn the language, it will speed up the process of mastering it. They also mentioned the combination of new vocabulary and music. When children sing Mandarin songs, they also entrench the sounds and it helps them to remember the words. Even using the voice to count and recite the names of the days was useful in practising sounds. It was also clear that the techniques used to learn Mandarin, such as repetition, songs, technology and online activities, can be extended to learn other subjects too. However, Tse et al. (2007:380) explain that parents are inclined to make their children rehearse the characters which they are required to learn. However, the parents are disappointed when their children are expected to memorise characters that are newly learnt individually and that are not connected to a theme, or that are not connected to the previously learnt character structures.

\section{P14 said:}

'She sings songs in the bath, she talks to her brother - it was difficult at first but now she finds it easier - it has helped her focus and concentrate for long periods of time in general. She can count up to 1000 in Mandarin. She can communicate, yet in a limited way - learning Chinese characters requires focus; the child is able to be more attentive in other subjects too.' (P14, mother, Grade 5).

The learners confirmed that they do homework. They receive a worksheet with characters to practise. The worksheet has blocks on them and the learners have to practise writing each character block by block. In order to maintain their interest, the teacher recommends that they need to watch Chinese movies and listen to Chinese music with characters and Pinyin and English subtitles on - she extends their learning to practical interfaces. She said, 'More time and a learnerfriendly environment to support learning characters and appropriate visual aids and animated characters could help learners to understand and memorise'. The learners who had sufficient support referred to the parents going online with them and learning new words. One learner said his father is learning Mandarin as he also visits China from time to time on business. Some learners revealed that the parents do not understand Chinese themselves and are unfortunately unable to help them with their work. However, they said that they taught their parents and that was fun. The joint mission of mastering Mandarin was a way to bond and share interests. Their parents' support and involvement were however noted as a motivational factor. In Li's (2013:283) study, she found that learners were seldom given homework to practise what they have learnt, which affected their expectations of learning characters.

However, there were learners who were less fortunate and who had to work out meanings on their own. These learners learnt to take responsibility for their own learning and made the most of the learning opportunities, even other languages were mentioned as there was an interest in becoming multilingual and not only bilingual.

\section{Strengths and limitations}

As the recent development of teaching Chinese as a second (additional) language (TCSL) in South Africa and it being underrepresented in the area of TCSL research, this study is welcome as an addition to the literature. However, the scope of our research is broad and the teaching strategies are nothing new, but it calls for a more in-depth evaluation, which is beyond the scope of this article because of the word limit of the journal.

\section{Conclusion}

We endeavoured to answer the research questions formulated for this study and established that the teacher uses a communicative approach. Whilst most learners did not enjoy repeated practice, others were resistant towards learning new characters whilst still trying to master those characters that they had already been exposed to. Yet few others found Pinyin and the tones more difficult to learn and preferred learning the characters. Some learners indicated that they preferred learning the characters through the use of English. 
The teacher in our study believes in introducing Pinyin first; however, in the workbooks, each chapter has a set of characters that needs to be learnt. Consequently, they internalise the characters and in so doing build a character bank. It is cautioned that phonic symbols should not be learnt before the characters. When teaching the characters, the teacher first needs to clarify the strokes and the rules of writing characters, then the radicals and finally the associations. The learners practise writing on worksheets with blocks on it in which they write a character in each block making use of the numerical order of writing the character step by step. Learners also make use of colour coding and accompanying Pinyin and English where needed. The sounds of the characters are learnt by pronouncing them repeatedly. Fun activities such as games, drill work in writing the characters and a great deal of revision are the crux of learning the characters. Practise, practise, practise. This includes the use of visual aids, such as voiced words on the computer as well as animated characters, to aid memorisation. Learners make use of stroke order for looking up words in the dictionary. Pinyin appears to be an indispensable aid in learning the characters, as once the characters have been learnt the accompanying Pinyin is discarded. Group work and listening tests enhance the learning of pronunciation. Making use of association, such as the number 4 which looks like a window, singing Mandarin songs, using the Internet for translation and games were also used by the learners to facilitate learning characters.

The researchers in this study identified a number of challenges in teaching and learning Chinese characters. The teacher's response in the questionnaire was that there is no scheme of work designed for this undertaking; however, she follows a thematic, structured plan. It is apparent that the learners in this case study experienced many of the difficulties identified by Shen (2005), that is, the Chinese orthography and the graphic configurations (no soundscript correspondence) and Schmidt's (2002) reference to the complicated characters which comprise a number of strokes. The main challenge that the teacher in this study experienced is when the learners did not follow the sequences of writing a character. For some learners, remembering the numerical sequence of writing the strokes in the characters caused difficulty, which was a challenge for the Chinese teacher in navigating effective ways to overcome this difficulty. A major barrier to the learning and practising of the characters was the duration of the lessons, which lasted only $30 \mathrm{~min}$ a day. Some learners had the advantage of being exposed to Mandarin longer than others, having been in the school since pre-school, whilst others only started learning Mandarin at the beginning of the year. Despite having been exposed to the language since pre-school, there was still a need for more teaching time and support.

Whilst some parents reported that their children showed adequate progress and were able to help themselves, others indicated that their children had difficulties in learning the characters. The parents felt that they were not in a position to help their children, and even though adult classes were offered on Saturdays the parents were unable to attend them because of time constraints.

The Pinyin-annotated approach serves as a crutch in learning to write the characters and can be used effectively. However, when Pinyin is no longer used, the learners become confused and start panicking as they need to learn new characters. The learners are then expected to work out their meaning and remember what the sequence of writing the characters is. Learners also find it difficult to remember the correct tones which indicate the pronunciation of the words. Despite these challenges, the Chinese teacher in this study indicated that Pinyin should be taught first, in the beginning of Chinese character learning.

The perceptual approach offered by Tse et al. $(2007: 375,384)$ is highly recommended. The learner starts with his or her home language. Chinese characters are taught using meaningful contexts, integrating language learning and awareness and learners' perceptions of what they need to learn are stimulated. Learners are made aware of the structural features of the Chinese characters and how they are similar or different and that they can be grouped into clusters which are ways to learn the characters easily.

Whilst the learners in this study used the majority of the learning strategies offered by Shen (2005:57) in the literature study, the remaining strategies that did not feature in the findings would be worthwhile utilising.

\section{Recommendations}

It is important for future research to investigate what role the L1 (mainly English) plays in the acquisition of Chinese character tasks for beginner learners in primary schools. It would be advantageous to replicate Shen's (2005) research (permission granted) in a comparative study, by using the strategy inventory for character learning and the survey for Chinese character learning strategies simultaneously in a South African context, as well as in a Chinese context. The aim of this collaborative research would compare the findings and explore similarities and differences, culminating in substantial context-specific recommendations for learning Chinese characters.

\section{Acknowledgements}

The authors would like to thank Dr Wang Linpu from the Zhejiang International Studies University, Hangzhou, and Me Julie Hwang (student), University of South Africa, for their support in inserting the Chinese characters where needed.

\section{Competing interests}

The authors declare that they have no financial or personal relationships that may have inappropriately influenced them in writing this article. 


\section{Author's contributions}

N.M.N. was responsible for the overall layout of the article, the abstract, literature review, methodology, writing up of findings, conclusions and recommendations. S.K. and L.L. made inputs, corrections and additions where necessary. All three authors participated in the data collection.

\section{References}

AllAfrica.com, 2016, SA Eyes Mass Mandarin Teaching in Schools in Five Years - Minister AllAfrica Global Media Provided by SyndiGate Media Inc., United States, viewed n.d., from http://www.chinese-embassy.org.za/eng/zngx/whjl/t1357520.htm

Department of Basic Education (DBE), 2015, 'Republic of South Africa. Regulation Gazette No. 10396', Government Gazette 597(38589), 1-8.

Ding, S. \& Saunders, R.A., 2006, Talking up China: An analysis of China's rising cultural power and global promotion of the Chinese language', East Asia 23(2), 3-33. https://doi.org/10.1007/s12140-006-0021-2

Efron, S., Efron, E. \& Ravid, R., 2013, Action research: A practical guide, Guilford New York.

Hau-Yoon, L., 1999, Mandarin Chinese - Rumen Hanyu. Study Guide 1 for Man101R, University of South Africa, Pretoria.

Li, L., 2013, 'The teaching and learning of Chinese in English primary schools: Five exploratory case studies in the West Midlands region of the UK', PhD thesis, University of Warwick, University of Warwick Institutional Repository, Coventry.

McAteer, M., 2013, Action research in education, SAGE, Los Angeles, CA.

McBride-Chang, C., Lin, D., Liu, P.D., Aram, D., Levin, I., Cho, J. et al., 2012, 'The $A B C$ 's of Chinese: Maternal mediation of Pinyin for Chinese children's early literacy skills', Read Writ 25(1), 283-300. https://doi.org/10.1007/s11145-010literacy

McBride, C.A., 2016, 'Is Chinese special? Four aspects of Chinese literacy acquisition that might distinguish learning Chinese from learning alphabetic orthographies', Educational Psychology Review 28(3), 523-549. https://doi.org/10/1007/s10648Educational

MacMillan, J.H. \& Schumacher, S., 2014, Research in education: Evidence-based inquiry, 7th edn., Pearson, Essex.
Moeller, A.K. \& Catalano, T., 2015, 'Foreign language teaching and learning', in J.D. Wright (ed.). International encyclopaedia of the social \& behavioural sciences, $2 \mathrm{nd}$ edn., vol. 9, pp. 327-332, Pergamon Press (Elsevier Ltd.), Oxford.

Poole, F. \& Sung, K., 2015, 'Three approaches to beginning Chinese instruction and their effects on oral development and character recognition', Eurasian Journal of Applied Linguistics 1, 59-75. https://doi.org/10.32601/ejal.460599

Schmidt, J., 2002, New practical Chinese reader: NOTCFL, Beijing Language and Culture University Press, Beijing.

Shen, H.H., 2005, 'An investigation of Chinese-character learning strategies among non-native speakers of Chinese', System 33, 49-68. https://doi.org/10.1016/j system.2004.11.001

Sung, K. \& Wu, H., 2011, 'Factors influencing the learning of Chinese characters', International Journal of Bilingual Education and Bilingualism 14(6), 683-700. http://doi.org/10.1080/13670050.2011.57165

Tan, L.H., Spinks, J.A., Eden, G.F., Perfetti, C.A. \& Siok, W.T., 2005, 'Reading depends on writing, in Chinese', Proceedings of the National Academy of Sciences of the United States of America 102(24), 8781-8785. http://doi.org/10.1073/pnas.0503523102

Tong, X., Yip, J.H. \& Yip, Y., 2015, 'Cracking the Chinese character: Radical sensitivity in learners of Chinese as a foreign language and its relationship to Chinese word reading', Reading and Writing: An Interdisciplinary Journal 28(2), 159-181. http:// reading, Reading and Writing: An Interdis-1007/s11145-014-9519-y

Tse, S., Marton, F., Ki, W.W. \& Loh, E.K.Y., 2007, 'An integrative perceptual approach for teaching Chinese characters', Instructional Science 35, 375-406. http://doi. org/10.1007/s11251-006-9011-4.

Vaezi, R., Tabatabaei, S. \& Bakhtiarvand, M., 2014, 'A comparative study of speechacts in the textbooks by native and non-native speakers: A pragmatic analysis of New Interchange Series vs. Locally-made EFL textbooks', Theory and Practice in Language Studies 4(1), 167-180. http://doi.org/10.4304/tpls.4.1.167-180

Wilson, E., 2009, School-based research: A guide for education students, Sage, Los Angeles, CA.

Xu, J., Li, B. \& Curtis, A., 2015, 'Validating an English language teaching reflection inventory in a Chinese EFL context', System 49, 50-60. https://doi.org/10.1016/j/ system.2014.10.014

Xu, Y., Perfetti, C.A. \& Chang, L.Y., 2014, 'The effect of radical-based grouping in character learning in Chinese as a foreign language', The Modern Language Journal 93(3), 773-793. https://doi.org/10.1111/j.1540-4781.2014.12122.x

Yongbing, L., 2005, 'A pedagogy for digraphia: An analysis of the impact of Pinyin on literacy teaching in China and it implication for curricular and pedagogical on literacy teaching in China and it implication for curricular and pedagogical https://eric.ed.gov/?id=EJ728329

Zhilong, F., 2000, Essential Chinese for travellers, Regent, Hong Kong. 


\section{Appendix 1}

\section{Learner questionnaire}

- What do you do to help yourself to understand the characters after the teacher has taught the character?

- Do you take the characters apart for you to learn them? If so, draw in the block next to each character how you do it:

\section{好人我}

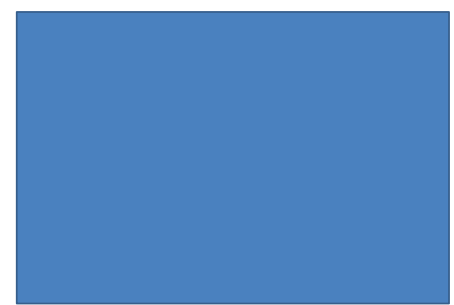

人

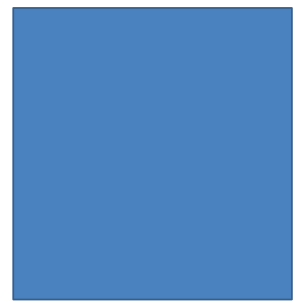

我

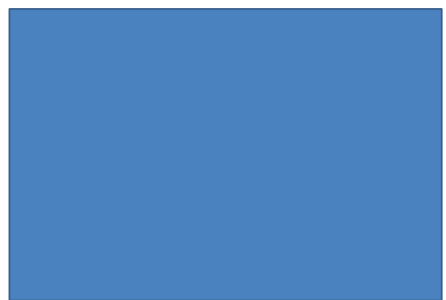

- Explain how you memorise a character.

- How do you learn the sounds, shapes and meaning of the characters?

- Complete the sentence - you can continue at the back of the page: I practise the new character by 